\title{
CULTURE AND EDUCATION IN A PRAGMATIC CONTEXT'
}

\author{
Jacob L. Mey
}

\section{ABSTRACT}

One area where cultures clash is education. Over the years, we have been witness to such movements as 'English Only' in the US (originating in California and Florida, but now operating in a number of other states as well), or the acrimonious European disputes over how much of 'foreign' culture can be allowed into the school's environment (head scarves on the playgrounds, religious symbols like crosses worn around the neck, prayer in the classrooms, and not least use of other languages than the 'official' one in teaching and socializing). Pragmatics, by placing the emphasis on the users of language in culture, defuses the potentially explosive elements in such clashes by stressing the need to respect the individual's options in face of the collective cultural pressure. This is especially important in an area such as education, where schools have historically been used to propagate the 'domestic' culture over other cultures, the latter being considered as foreign imports. In a pragmatic view of education, teachers and students should be culture sharers, rather than the former considering themselves exclusively as the rightful owners and proprietary protectors of a culture along with its language.

Key words: Discourse completion test, bilingual education, culture, pragmatic acts.

\section{Introducing the problem: The battlefields of CUlture}

It is often said that we do not learn (or teach) for the purposes of the school, but for the sake of life: Non scholae sed vitae discimus. It is interesting to confront this age-old adage with current disputes over bilingual education and its funding in places like California, Florida, or Texas, as well as with actual practices in education, where in the name of a particular ideology, students are forced to opt in or ship out (like in the case of the infamous 'head scarf' controversy in the French school system, now officially terminated by a Ministerial Decree forbidding the wearing of this traditional cultural symbol).

1. A preliminary version of this article was delivered as a public lecture at the University of Brasília, 22 October 2004. 
A pragmatic solution to these problems outlines an approach that allows the users of a culture to claim the validity of their own culture; at the same time, it asks them to respect the right of others to define and defend theirs. As some of the most acrimonious cultural debates lately have centered around education, the question of whose culture is informing whose education is central, precisely in (but not limited to) this area, with repercussions throughout the whole of society. Pragmatics helps us to find a way out of the cultural clashes we are witness to in our days, by solving some of the problems that have beset the teaching and learning of languages, including in particular the teaching of English as a foreign language (TEFL).

\section{Culture}

\subsection{What is it?}

First, we have to raise the question what culture is, and what it does to us. Several options are open here:

- Culture seen as a possession: this is when we talk about 'national', 'regional', 'tribal', etc. culture. Culture in this sense is thought of as belonging, by birthright as it were, to a nation or tribe. The concept can also be extended to any group of people who consider themselves as constituting a meaningful unit. Speaking dialectically, the culture gets its meaning from the unit it is embedded in; conversely, the unit receives its meaning by the culture it embodies. Thus we can speak not only of a French culture or a Chinese culture, but of the culture of jazz, of food, of golf, and so on.

- Culture considered as self-expression, especially as seen in a phenomenon like the so-called 'youth culture' of the sixties and seventies. In this kind of understanding, a culture serves to express a deeper reality about the group or its members than can be observed on the surface. In this sense, too, the culture resides deep down in one like the roots of a tree, it cannot be removed from its 'bearers'. As Thomas Mann said, on arriving by ship to New York in 1939, 'I carry my culture with me' (I will come back to this quote below).

- Culture as a divider. Naturally, such an attitude very easily morphs into a feeling that we, the culture owners, or 'carriers', are better (off) than those who do not own (a particular) culture. It's 'us' against 'them', 'the others'. This attitude quickly becomes a problem in the case of 'natives' vs. non-natives, the 'autochthonous' members vs. the 'allochthonous' immigrants, as we will see in the sequel. 
- Culture as resistance, often labeled the 'counter-culture'. Here, defining oneself through and in a culture may become the expression of a general 'discomfort with civilization', in Freud's terms; in extreme cases, it may lead to violence and aggression, either verbal or physical, even armed. Many of the gangs in big cities see themselves as representing a sub-culture of the 'counter' kind, often rooted in some real or mythical ethnic or national tradition (compare the Jamaican Rastafari, the 'skinhead' culture, the rockers, the bikers, etc.; a study of the various symbols these groups use to define themselves, while interesting in itself, would take us too far afield, though).

- Culture as battlefield. This is the concept that (among other things) has led to attitudes such as represented by the German Kulturkampf under Chancellor Otto von Bismarck ${ }^{2}$. The notion that culture is something that one battles for, or against, is not new: many wars have been fought to preserve the 'European' or some national heritage (cf. the battle against 'un-American' tendencies from the McCarthy period, which unfortunately seems to have gotten a renaissance these days with the post 9/11 scare in the US). Even Hitler saw himself as the protector of Western (read: German) civilization, the Occident or 'Abendland', against the Asian hordes embodying all sorts of horrors, especially 'godless bolshevism'.

- Culture as a means of repression; this is the so-called 'hegemonic' culture (compare the debates of the fifties - about U vs. non-U language in England; the values accorded to accents or dialects; the exclusion of people on account of their socio-cultural provenience; and so on) ${ }^{3}$. On a lesser scale, the battles of cultures happen every day in our environments: to be allowed to even speak one's own language in the workplace is not always recognized as a human right. Linguistic oppression is found in many shades, from out and out 'geno-/linguicide', killing off a language along with the people who happen to speak the wrong dialect (as reported in the Biblical book of Joshua, ch. 15) to firing MexicanAmerican employees who break company rules by speaking Spanish in their lunch breaks (as in an actual case reported from Dallas, Texas).

2.Originally a movement in 19th century Imperial Germany aiming to purge the Reich from all extraneous, 'ultra-montanist' influences, such as represented by the Catholic Church and especially its stalwart legionnaires, the Jesuits.

3.Compare the old joke:

"If you're going for a job interview in London, and you were born in Manchester or Birmingham, you may want to take a fast course in sign language". 


\subsection{Problems with culture}

Next, the question is why there should be problems with culture (Freud's 'discomfort of civilization'). Here, too, belongs the question of how to handle such problems.

Again, several issues need to be raised.

- The intra- vs. the inter-cultural. If one is 'born' into a culture, one is by definition 'intra-cultural'. Culture is then not problematic; in fact, we rarely are aware that there is such a thing as a particular 'culture': we are simply different from, and better than, other people in important respects. Many (not only 'primitive') people simply call themselves 'the people': Eskimos are inuit 'people', Germans are Deutschen (cf. the Gothic term thiuda 'folk'). In contrast, the intercultural is where potential problems originate; in the meeting of cultures, not only good things arise, but also strife and bad feelings: the others are not only 'other', that is, 'different', but also 'other', in the sense of 'inferior' (the 'barbarians', as the Greek called those who spoke a different language $)^{4}$.

- Moving a culture across borders. If I am in possession of a culture (being inside of a culture, 'intra-cultural'), then what does it take to become 'intercultural' (and why should I)? Can I relocate without losing my culture? Can cultures be transplanted just like plants or trees? Notice here the inherent limitations on all kinds of transplantation, not only in the case of plants and trees: there are constraints of age, environment, climate and soil, etc. Conversely, the question is how transplantation will affect the new environment, in a dialectic movement. (A botanical analogy: plants like Artemisia or Eucalyptus release certain toxins into the soil in order to kill off potential and actual competitors for the common life space.)

- If one accepts culture relocation as a possibility, how much of the foreign culture (e.g. a language) should be allowed in, and where should it be allowed to exist (or, in the case of a language: practiced)? Here in particular, the intercultural poses some serious problems, as in the case of Denmark, where in the tabloid media parlance, the term 'bilingual' (tosproget) has become synonymous with 'member of an immigrant gang' or simply 'juvenile criminal'). Also, are the place and expansion

4.Thucydides, in the first book of his Histories, openly sneers at the 'barbaric' nations around him who didn't take their clothes off when exercising or practicing sports. 
of a culture matters that can be decided by majority vote? What if a Muslim majority in a southern Philippine village decides that all women will have to wear veils? Or what of the fundamentalist Christian culture that now starts to pervade US public life, not only as seen in the Bush White House Bible study meetings ('you're not one of us if you don't regularly participate in our study group'), but even more ominously (because fully or partially institutionalized), in the fundamentalist exclusion of other religious beliefs, as it is currently practiced in official environments such as the US Air Force Academy ${ }^{5}$ ? Should one simply, in culture as in other areas of our lives, adapt to the environment? And if one cannot live with that, how can one 'have a life'? In other words, is it 'Shape up or ship out' (or, as the old expression has it, 'When in Rome, do as the Romans do')?

- Finally, one might again raise the question: Where does culture reside? Is there such a thing as a 'culture-carrier' (an expression much vilified by its use in Nazi contexts). Take the case of Thomas Mann who, on arriving in New York, was quite certain that the culture he 'possessed' was not only his own, but one that he carried with him, like somebody would carry important books with him in his suitcase. Mann saw himself as a cultural missionary, coming to teach the Americans a healthy dose of good old European culture. But he was unable to fulfill his mission, being a minority of one, just as he had been a minority in his own country, Germany. In culture and in democracy, majority rules, and the majority is able to manipulate minorities out of existence by isolating them or exiling them, taking away their environment in a kind of cultural 'redistricting'. (Typical American quote: 'This is my land, this is your land/From California, to New York Island/ ... This land was made for you and me' - but what about the 'First People'?) ${ }^{6}$.

5.According to a Los Angeles Times report, "the Academy has essentially established Christianity as its official religion". Those who are not 'born again' are told by some chaplains that they will burn in the fires of hell; even the football coach urges his players to 'join Team Jesus Christ'. (Michael Ventura, 'Letters@3 AM', The Austin Chronicle, April 28, 2006, p. 36, quoting from The Week, June 3, 2005, p. 16)

My own daughter Sara and her husband Bryan, practicing veterinarians in Grand Rapids, Mich., had to leave town, as they couldn't stomach a cultural environment where Scripture oozed out of every pore among the Evangelical locals, as soon as any matters of interest came up for discussion.

6.On the problem of the intra vs. the inter-cultural, see now Mey (2004). 


\section{A particular cUltural context: Education AND ITS PROBLEMS}

\subsection{General on education}

- Very broadly understood, and based on the etymology (Latin $e(x)$ 'out'; root $d u c$ - 'lead, bring') as: 'bringing out [the best in people]: 'e-ducation'.

- But there is also another etymological implication, as in the word: 'in-duction': 'bring into', that is: 'incorporate people into' (e.g. the Country Music Hall of Fame, or Rotary International). Here, we can speak of education as a way of acquiring membership in a society's cultural club.

- In a related sense, education is a means to help preserve the cultural identity of a community, a tribe, or a nation, by emphasizing its cultural traditions, rituals, customs, food, clothing, etc.

- As a consequence, education (in addition to its aspects of vocational and professional training) often becomes a means of 'invisible' qualification, a 'ticket' to the 'good' society, better jobs, communal participation, and so on; the results of education (as e.g. manifested in writing skills, spelling competence, the 'right' accent) serve as an 'index' of belonging to the proper social stratum (educational results being seen as proportional to the amount of time and energy that somebody has been able to spend on his or her training).

- The latter aspect implies naturally that education also functions as a means to preserve social and racial barriers (social 'apartheid' starts already in kindergarten and is promoted throughout the entire school system).

\subsection{Problems of culture in (educational) context}

On the basis of the above, we can identify a number of cultural problems that arise in an educational context.

- The first problem is to determine whose culture we are talking about when we deal with matters of education. Is it solely the culture of the 'natives', often called the 'autochthonous', in opposition to the 'allochthonous', those who are born on another (as opposed to 'the own') soil (chthon in Greek), or should other cultures be accorded equal rights and opportunities? 
- Next, there is the problem of cultural autonomy and independence. The schools and other educational institutions are often a battleground in this respect; culture is expressed, but can also be repressed through educational means. For instance, education in the mother language is often seen as a threat to the hegemonic culture, and is therefore forbidden; cases in point are Basque in Spain, Finnish in Sweden, Kurdic in Turkey) ${ }^{7}$.

- In mirror-image fashion, we often find, among cultural minorities, a certain resistance to 'mainstream' education, which by them is considered as a means of social and cultural oppression. Typical cases are the discussions about Black English as a means of instruction in US primary schools (the 'Ebonics' case) or the failure of programs such as 'Head Start'".

- Conversely, on the other hand, we often find, among indigenous people (and also among some of the European immigrant communities that originated in immigration), a resistance to being educated in the proper culture, which is seen as an obstruction to advancement in the dominant society. One famous case concerns the resistance by the Guaraní in interior São Paulo State, Brazil, against being instructed in their own language: they preferred to be 'alphabetized' in Portuguese, the language of prestige (Cavalcanti, 2000).

- When it comes to educating (young) people in a drive to preserve a minority, often 'endangered' culture, such preservation usually happens on the dominant majority's terms. Indian reservations in the US are kept intact for the tourist trade (often the only means of survival for the people in question), and 'cultural ghettoes' are artificially maintained free from outside influence. For instance, the Dutch East Indies colonial government forbade any outside intervention on the island of Bali, thought of as a not-to-be-disturbed specimen of autochthonous, Buddhist

7. The repression often extends beyond the national-cultural pale. In 1974, Turkish authorities in Denmark tried to prevent the teaching of Kurdic at a two-week seminar organized in Denmark by the Danish Teachers' Association. The Turks sent employees of the Embassy to the location where the courses were held, and tried to intimidate the teaching personnel and the students - of course to no avail.

8. 'Ebonics' was the name given to the Black English variety that at one time was promulgated as the teaching standard in Oakland, Calif. schools. The ensuing debate engulfed the whole of the US, but it seems almost forgotten today. ('Ebonics' alludes to 'ebony', a metaphorical expression for 'Black', as in the name of the Black American bi-weekly magazine Ebony). 
culture; as a result, no missionary activities were allowed there. (By an ironic twist of fate, this very act of preserving the indigenous culture has rendered Bali one of the more attractive current tourist destinations among the Australian, European, and American rich).

- In all these cases, the educational problems are not alone. School unrest spills over into larger society, when groups of un- or half-educated youth exert pressure on the society at large by acts of vandalism (graffiti, destruction of public property, gang wars); but also conversely: education without a proper follow-up in the form of sensible employment results in well-educated alienees turning their backs on society and resorting to violence and terror as an outlet for their frustrations. In this way, the economic structures that caused the decay of the educational system or the neglect of career opportunities for the schooled 'strike back' at society: repairing a social structure is always more costly than preventing its collapse.

\section{The teaching and acquisition of foreign languages as a pragmatic- CULTURAL PROBLEM}

As we have seen in the previous section, the main problems of culture in an educational context become visibly demonstrated in the area of (second) language acquisition and (second) language teaching (SLA, TESOL, TEFL etc.). The question here is, again: Whose language is being acquired, and whose language are we going to teach? And: How can we avoid the oppressive aspects of our teaching, while at the same time imparting a high quality language education? These and similar questions have been raised opportunely and appropriately by authors such as Martin-Jones \& Heller in their volume Voices of Authority (2000); below, I will discuss some of the implications of the various approaches.

\subsection{Earlier approaches and a 'mini-revolution'}

What I have said so far has significant implications for the study of language, and in particular for the teaching of languages (e.g. in TEFL, and in general, SLA). What seems to be the problem?

Earlier, teaching foreign languages was basically synonymous with teaching grammar: the cases of Latin and German, the irregular verbs of English or Hebrew and so on; in addition, emphasis was placed on acquiring a basic, 'literate' vocabulary. One never asked, or taught the students, how the grammatical devices and the words they had memorized, were used in communication. As 
a result, people could be proficient in grammar and have a large vocabulary without being able to utter a single sentence in the foreign language.

A pragmatic 'mini-revolution' took place with the advent of the so called 'communicative method'. Here, the goal was not primarily to observe grammatical rules, but to get a message across. What was forgotten, however, was that more complicated messages (like beyond ordering a drink in a bar) often required a more complicated vocabulary, and not least a certain command of the grammar. In addition, there is the lack of prestige attached to using a reduced or truncated form of the language (like Basic English) or expressing oneself in an 'interlanguage' of some kind (either an established pidgin like 'Pasar [market] Malay' or an acquired, personal intermediary-stage interlanguage). The use of such a variety often indexes an improper context, and may adversely affect the learning situation as well as communication itself. In other words, the proponents of the communicative method are blind to the fact that the problem is not one of merely communicating (or 'transferring information', as it used to be called, and still seems to be emphasized by many teachers), but also, and more importantly, of which things are communicated to whom, and how such a communication proceeds.

The crux of the problem is that real communication presupposes a real communicative situation. Such a situation occurs normally in places where the language to be acquired is used in everyday communication; but by the same token, to participate in, or create, such a situation is an impossibility for most learners, as not everybody can afford to travel to the mother country of the language they want to acquire. To remedy that impasse, applied linguistics (especially of the 'contrastive' kind), came up with the method of the imagined conversation in the foreign language, in a communicative situation based on role play. Here, learners were given certain tasks to accomplish while using the foreign language: e.g., some were supposed to act as police in a street traffic situation, while others were asked to imagine themselves in the roles of pedestrians, car drivers, bicyclists, etc.

With regard to our topic, 'real' communication and its pragmatic aspects, nothing much was achieved by using the communicative method beyond the acquisition of a certain restricted fluency in the foreign language. Communication was limited to the 'learnt' situations; the foreign language as such remained foreign. Learners basically transferred a small piece of their own culture (e.g. how to behave in a traffic situation) to a similar situation in the foreign culture, and formulated their 'intercultural' understanding of the situation, using only the foreign language's words and sentences. The foreign situation as such was not a serious part of this communicative behavior; and it certainly was not its required, pragmatic foundation. 


\subsection{Speech acts and SLA: the DCT}

The assumption that speech acts must be found in every culture and language seems innocuous at first, and in a sense, it is: If we admit that speech always 'does' something, then it is legitimate to ask what particular 'doings' are related to particular 'sayings', or speech acts. The problem is that we cannot isolate a speech act from its context, and even if we think we have found the perfect intercultural formula for a particular act, it may turn out that the correspondence was superficial at most, or even non-existent (see Mey, 2001: 215).

When the theory of speech acts began to be applied to real-life situations, it was soon recognized that speech acts only have validity in a particular situation. The theory of the 'situated speech act' became an important step in this process (for details, see Mey, 2001: ch. 8). With regard to the educational problems of the kind I have outlined in the preceding section, the thought was that educational situations, too, could be characterized in terms of the speech acts that occurred in them. Conversely, the question was raised to what extent a certain speech act could be used in various situations, in particular, in situations where another language was the medium of communication. Take, for instance, the speech act of 'requesting' (either a banal request like asking to borrow a person's pen, or one concerning a more complicated matter, such as having one's professor read one's term paper): do such requests only differ in the wording used, or is there (much) more involved (like situational knowhow)? If one could just assign speech acts different wordings in different languages, the problem of intercultural communication in education would be partly solved. To obviate the problem of the situation, one could then try and have the speech act in question 'happen' in a situation that was perceived as normal and legitimate by the participants. In the efforts to realize this idea, the 'discourse completion test' (DCT) was invented.

The DCT, as we know it today, was an ingenious method, devised by Blum-Kulka and her collaborators (1989) ${ }^{9}$. The method basically consisted in creating a (written) 'role play' situation, in which the participants are asked

9. The 'discourse completion test' was later renamed 'discourse completion task' due to negative connotations associated with the word 'test'. Also, the fact that a task is devised to find out what a learner knows, whereas the purpose of a test is mainly to ascertain what a learner does not know, makes the term 'test' less suitable in this context. Moreover, given the large number of recent adaptations of the 'classic' DCT, the new versions are now generally referred to as 'production questionnaires' (abbreviated 'PQ'; see, e.g. Johnston et al., 1998; Sasaki, 1998; Kasper, 2000; Yuan, 2001). (I owe these observations and references to Anne Barron in personal communication). 
to engage in a conversation about a certain, mundane happening or problem (such as having to borrow another person's car, or complaining to one's roommate that the dishes get stacked up in the sink). The experimenters gave the participants the 'first part' of the conversation, along with a description of the situation, and asked them to 'complete' the situation by supplying a suitable continuation of the 'discourse'. Here is an example of such a task ${ }^{10}$ :

You come home at night to your dorm room and find that your roommate again has 'forgotten' to do the dishes. You cannot even find a single clean cup and you want to make yourself a cup of coffee. Your roommate comes into the kitchen, and says: "Oh - I should have taken care of those dishes". What do you say?

Having the informants complete this 'mini-discourse' in several languages (such as American English, Japanese, Israeli Hebrew, etc.), Blum-Kulka and her co-workers were able to establish certain cross-cultural correspondences for a particular speech act (in the above example, it might be the act of accepting or respectively rejecting the implicit apology that was being offered). The assumption was that, by administering the test to a sufficient number of subjects across cultures and languages, and having informants from different languages and cultures complete the discourse in different ways, we may be able to discover which speech acts are possible or favored under which circumstances, that is: which words go together with which acts across cultures ${ }^{11}$. More important in this connection, however, is another, theoretical problem: To what extent can speech acts be transferred from language to language, from culture to culture, like pre-packaged quanta of information ('have speech act, will travel')? The latter problem was never considered seriously by the protagonists of the DCT; I will discuss the issues related to this matter in the next section.

\subsection{Discourse Completion Problems}

The DCT has become immensely popular among workers in applied linguistics, and the number of studies using this method has been continually growing over the past decade (for examples, see Mey, 2001: ch. 10). However, there are some inherent problems in this test; I will single out a few of these below for discussion.

10. Not due to Blum-Kulka et al. (1989).

11. One does not have to restrict oneself here to 'speech acts' as they are conceived of 'canonically' in the sense of Searle and others; rather, I would suggest to focus on what I call the 'pragmatic act' (Mey, 2001: ch. 8; see also below). 


\subsubsection{The notion of 'discourse' in DCT}

The first problem (which is, so to speak 'baked into' the very nature of the DCT) is the use of the word 'discourse' in the sense of: 'a stretch of talk longer than a single utterance'. Discourse, in this sense, is no more than a piece of 'mini-text', set off from the rest of the world in splendid isolation. The conditions under which the completion of this 'discourse' takes place are those of applied psychology, clinically and experimentally removed from life's realities; the latter being re-enacted only through the researcher's imaginative efforts, in which the subjects are supposed to co-engage. Moreover, as pointed out among others by Yi Yuan (2001), the amount of response that DCT generate is standardly inferior (quantitatively as well as qualitatively) to what is produced in natural language interaction (2001: 272).

\subsubsection{Cross-language speech acts: similarity or circularity?}

In contrast to this, another view of discourse has it that "the conditions ... place[d] on the human practice of meaning production make discourse different from a simple collection of ... sentences or utterances" (Mey, 2001: 191). As Mumby \& Stohl remark, discourse is "the ensemble of phenomena in and through which social production of meaning takes place, an ensemble which constitutes society as such" (1991: 315; my emphasis). Discourse, in this sense, is not just something that happens; rather, it makes things happen in that it furnishes us with the elements from which we build our worlds. And inasmuch as these worlds are by definition different, the whole purpose of the DCT seems either self-fulfilling or circular: in order to establish correspondences cross-world wise, we have to rely on discourse (completed in ways varying in accordance with the norms in different worlds). But since the 'discourse' is constitutive of those worlds, the tests may either be used to show (vacuously) that there exist cross-culturally identical speech acts (which we already knew, by our circular assumption), or to show that we can identify certain speech acts across cultures, given certain carefully arranged conditions that are supposed to be identical (which is begging the question). 


\subsection{3. 'Have speech act, will travel'}

A further problem has to do with the nature of 'speech acting' itself. Speech acts are not neatly encapsulated units of meaning, thought of as propositions, coupled with a certain additional flavor of questioning, ordering, promising, and so on. On the contrary, they are units of activity: a certain action is embedded both in the linguistic context and in the situation which makes the action possible. Neither are speech acts to be identified primarily by their actual verbal (or even 'canonical') expressions; the literature on the verbal manifestation of speech acts and its 'two-way canonicity' (often referred to as the 'illocutionary verb fallacy') has documented this issue with all desirable clarity (see Mey, 2001: 117).

The upshot of the discussions is that speech acts, however seemingly similar, do not travel well across languages and cultures; minimally, to stay in the metaphor, they have to carry a lot of cultural baggage with them in order to prosper in the new location. Hence, 'Beware of traveling speech acts!' is just as valid an admonition here as is the familiar warning issued by the US Agricultural Inspection at border crossings: 'Beware of traveling bugs!'.

The main question underlying these problems is the proper placing of the notion of situation in the practice of language teaching. An answer to this question will be adumbrated in the next section.

\section{4. (RE)SOLVING THE INTRA-INTERCULTURAL DILEMMA}

\section{1. Pragmatic competence vs. grammatical knowledge}

It is misguided to place the blame for the difficulties with tasks and tests such as the DCT on bad planning or insufficient design. Those factors are present, but they are not the main targets for improvement in the area of SLA, in particular the DCT. Rather, what is at stake is a heightened awareness of what really goes on in acquiring and exercising one's language's abilities: not so much, or even uniquely, mastering grammatical rules, or paradigmatically adopting certain speech acts, such as 'requests', 'apologies', etc., as acquiring a pragmatic competence, i.e., knowing how to use (or how not to use) the second language and other communicative devices in actual interaction. In other words, the emphasis in L2 teaching should be on pragmatic acts rather than on speech acts per se. (See further Section 4.2) 
One should also keep in mind here that the object of analysis is not the linguistic output of the learners, but their total communicative effort. And this again is a matter of mutual support between the participants in a learning situation. Conversation is not just exchange of information, as we have seen, but neither is it just 'talk': rather, it consists in the 'talkers' co-constructing a dialogic situation (one of the valuable points that the Conversation Analysts have been arguing, even though they not always grasped its full impact). In the same way, learning (both in the general sense, and as applied to SLA) is the product of an interactive, co-creative effort, realized in a situation of actual language use; constructing an abstract 'discourse', consisting mainly of imagined situations and possible, thought-up replies will not do.

Another matter is that exercises such as the DCT should not be viewed as principally oriented towards the assessment of a linguistic competence in the learners, but towards building up a pragmatic competence. We should also probe into the reasons why the collaborative effort sometimes fails, at other times is crowned with success; in other words, we should move from 'testing' to 'tasking', in keeping with the relabeling of the DCT itself as mentioned above, in footnote 9). The key notion here is that of collaboration, understood specifically as 'co-creation'.

\subsection{Co-creation in dialogue: Al and pragmatic acts}

To provide an answer to the question: What makes language education, in the sense of 'acquisition of a pragmatic/linguistic competence' successful, or merely possible? I would like to draw a parallel to efforts expended in a field that does not seem to be immediately related to the issue at hand: namely, research done on Artificial Intelligence (AI). What made these efforts, and the insights gathered from them, worthy of being funded by the spending authorities was the old dream of making a Golem, a machine that could act like a human, in particular when it came to using language. The practical importance of having such a device became especially urgent in the post-Sputnik days, when it turned out that American scientists had been unable to follow what the Russian aerospace engineers were doing, mainly because none of the Americans could understand or read Russian. So this is why back in the sixties, the first efforts in the field of AI focused on what was known as 'Machine Translation' (MT); and despite the fact that the dream never came true, it remains a fact that some of the original, rather primitive programs seemed to work (and still are being used by some agencies like the Canadian weather service in its bilingual program).

Another matter is what we can use the ideas of AI for in our connection. 
Here, it must be said that the underlying philosophy of those first efforts, that of the 'black box', as it was advocated in the early days of MT, is not very useful for our purposes ${ }^{12}$. In contrast, the essence of a sophisticated AI program is the creation of a self-sufficient model of general human activity, a Golem that can stand on its own feet, so to speak, and use its own head and arms: the modern robot. That means also that ideally such a model should be able to interact with a human user to the extent that the human user is not clear as to whether his or her interlocutor is a machine or a human (in the spirit of the so-called 'Turing test'). To obtain this state of affairs, the programmer must rely heavily on what is known or assumed about human competence in the cognitive sphere, in particular as such competence is embodied in language. So the first task is to figure out how humans understand their world and each other, and how they form this understanding in a mutually comprehensible wording.

However, the wording, no matter how successfully implemented, is not the whole story. We live in a world where the word plays a big role, but where language is absolutely not 'the last word' ${ }^{13}$. The workers in AI capitalized on an understanding of the world that is already there, in our minds, in the form of 'prefabricated' patterns of linguistic and general behavior. When we enter a mosque or a Japanese home, we know that we are expected to take off our shoes; however, in other cultures, taking off one's shoes on entering a place could be considered a sign of disrespect, or of unduly relaxed behavior. Similarly, we know how to express our gratitude, offer condolences or congratulations, thank for gifts, and so on and so forth, all in the appropriate situations and with the appropriate behavior. It is our world as 'cognized', the situations as pre-formed in our cultural and linguistic 'script', that determine our choice of, among other things, the words to be said and the actions to be taken.

To take a famous example from the world of cognitive modeling: the 'restaurant script'. On entering a restaurant, we know what is going to happen: a hostess will greet us, take us to our table and perhaps provide us with a menu, a waiter will come and take our order, we order and subsequently consume our food and beverages (in finer restaurants, the later activity may involve a sub-script where the wine list and the wine steward are important elements).

12. The idea of the 'black box' as a metaphor for the grammar of a language was first launched by Chomsky in 1957. One should be content with having a grammar with an input at one end and an output at the other; if these were satisfactorily matched, then the matching device (the 'black box') and what went on inside of it, were not interesting, except from a purely formal point of view (the 'rules' of the grammar).

13. Even though it has historically been declared to be the 'first', as in the opening chapter of the Gospel of St. John. 
Finally, we pay our bill (and in many countries, such as the US, tip the waiter or waitress) and leave.

All of this knowledge is instilled in our brains in a cognitive pattern of action, and accompanied by (or better, 'embodied in') the appropriate language. Conversely, the language we are using is not just the words themselves: it comprises the action that has become 'congealed' in them. When we contrast this view of using language with the way the language of action is represented in speech act theory, the difference is clear. Speech act theory starts with the language and asks: Given these words, what action can they perform? In contrast, a cognitive model such as used in AI takes its point of departure in the cultural and linguistic environment, and asks: What kind of language will be appropriate in this situation?

Thoughts like these have led to the development of the concept of 'pragmatic acts', as opposed to that of 'speech acts'. The notion is useful in combination with an application in reverse of the AI paradigm, where, upon constructing a model that emulates language use by humans, we turn the tables and ask what such a model, once constructed, can teach us about the way humans deal with their language. Initially, the model can be considered tabula rasa, that is, it has no ideas about the world as we see it, just as an inhabitant of another planet would have no ideas about the simplest things going on on our planet. For example, consider what we have to tell an inhabitant of Mars about how to use a simple household device such as a toaster. In order to even begin the explanation, we will have to reflect on what we are doing ourselves when putting a slice of bread in the toaster, and then 'translate' this knowledge-in-action to the extraterrestrial guest. We will then discover that our actions are completely conditioned by ("embodied in') the device and our past practices, and that our linguistic explanations only have a subordinate role in relation to those practices. A 'hands-on' experience, both in the case of the Martian and in the innumerable instances where we have to deal with modern machinery ourselves, is worth more than the booklet with its hundreds of pages of instruction; and even though the latter is of value to the experts, most regular users (e.g. of computer equipment) prefer the guidance of an expert to the written instructions ${ }^{14}$.

14. Compare the often heard, frustrated expression on the part of older, more experienced users, when confronted by a novice's questions: 'RTFB!' ('Read the f... ing book'). 


\subsection{Where to go next: The DCT revisited}

Returning to the original problem, the DCT, there seems to be a way of reconciling the insights that were gleaned through the use of this method with the views propounded in the previous section. If one could embody the situations that were only imagined, in an actual environment, the difficulty of how to realize a pragmatic act in a semi-natural surrounding would be greatly diminished. I'm thinking here in particular of programs in SLA that were structured as 'language baths', or in general, of language teaching methods based on 'immersion'.

Admitting that the original notion of a 'bath', as applied to foreign language teaching, was somewhat primitive, and in particular, that the emphasis on 'language' suffered from the same 'linguacentric' deficiency that I have singled out earlier, the idea of exposing the learner to a 'total situation', in analogy to what Erving Goffman (1961) called the 'total institution', has some attractive properties. And in a number of situations, this way of promoting SLA has proven to be eminently successful. Consider the case of the US military personnel during World War II, who were trained in 'language camps' that (with their - as we now can see somewhat misguided emphasis on 'drills') achieved precisely what must be the goal of any SLA program: to enable users in language. (The method, in addition, effectively demolished the common myth that Americans are constitutionally unable to learn any foreign languages). Or take the Israeli institution of ulpan, basically a language boot camp, where new immigrants were trained for six months in using Modern Hebrew in all situations of everyday life - a method that has proven to be extremely effective in creating a homogeneous Hebrew-speaking community out of the multifarious and sometimes conflict-ridden contingents of immigrants that flooded the Jewish state after independence in 1948.

Naturally, we should be aware of the limitations of these and similar educational programs: much depends on the people involved, on the programs themselves, and on the material presuppositions for their realization. In the case of the US military, a massive funding of the immersion programs in 'strategically important' languages was a necessary condition for their success ${ }^{15}$. In the Israeli case, the ulpan programs became partly dysfunctional after the countries of the former Soviet Union opened up for the emigration

15. After the war, this 'strategic' support continued in the form of 'Title IX' funding for language education. The events of 9/11 have triggered renewed official interest and funding for language programs such as Arabic. 
of its Jewish population to Israel. At that time, around one million new immigrants had to be accommodated and 'immersed' in language programs almost simultaneously over a short span of time. However, the partial failure of the immersion program in this case had nothing to do with the method itself, but was due to external factors such as lack of teaching and administrative personnel, inadequate lodging, and sheer numerical incompatibility. Conversely, the success of the method can be measured negatively by what happened due to the failure to absorb the new immigrants, not only languagewise: in Israel today, a new minority has emerged in the form of people who have their own sub-culture and do not want to be assimilated to Israeli society, even though many of them perform normal social functions, such as serving in the military or frequenting an institution of higher learning ${ }^{16}$. Typically, they are often the target of race-induced hate and violence, as in the case of the Russian immigrant soldier who was murdered in 1998 in a Tel Aviv bar for reasons that can only be classified as purely racist. (Source: the Israeli daily Ha-Arets, November 18, 1990).

\section{Conclusion: 'Pragmatic immersion'}

What I have been advocating for in the preceding is basically a technique of SLA known as 'linguistic immersion'. These 'language baths' became very popular especially in the seventies and eighties due to their success in Canadian language teaching programs. But to be fully effective, the 'bath' has to be pragmatically inspired and oriented; the immersion must show a pragmatic face. That is to say, our cognitive handling of a situation should emphasize the totality of the information that is available in the situation. As teachers, we should focus not only on the form of the words appropriate to the given goal, but also and more pronouncedly, on the actions that make up the situational context. Taking this approach will make us understand why classical speech act theory's insistence on the preferred, 'canonical' forms of speech acts (as opposed to indirect, 'deviant' expressions) makes no sense: in a way, all speech acts are 'indirect', being part of a greater whole, namely the situation, and depending on that situation for their fulfillment (Mey, 2001: 220). According to the classical theory, an indirect speech act is a speech act that does one thing while saying something else: "How do I know [somebody]

16. As in the case of the two Russian students who I talked with on the campus of the Haifa Technion in 1999. They summarized their situation in the following pithy formulation: "In the Soviet Union, we were Russian Jews. And in Israel today, we still are Russian Jews." 
has made a request when he only asked me a question about my abilities?", as Searle (somewhat rhetorically) queries (1975: 82). What the (indirect) speech act does, is clear from the situation, not primarily from the words; more often than not, we don't even think of the words we are saying as being semantically or syntactically appropriate to our goal, as when we, in order to get acquainted with a person, inquire as to how she or he is doing.

I will call this way of second language teaching and learning 'pragmatic immersion'; I believe it to be a useful way of solving some of the persistent problems I have identified earlier. Also, if I may be allowed to hearken back to the introductory section of my article, it should be clear now that such an approach is more than just another way of instilling some language abilities in learners; rather, it prepares learners not only for the learning situation itself, but for life beyond formal instruction. In this sense, we can indeed say that learning is not just for the school, but for life: Non scholae sed vitae discimus.

\section{References}

Blum-Kulka, S., House, J. \& Kasper, G. (Eds.). Cross-cultural pragmatics. Norwood, N.J: Ablex, 1989.

Cavalcanti, M. C. Collusion, resistance and reflexivity.

Indigenous teacher education in Brazil. In: Heller, M. \& Martin-Jones, M. (Eds.) 2000, pp. 317-333.

Goffman, E. Asylums. New York: Doubleday, 1961.

Heller, M. \& Martin-Jones, M. (Eds.). Voices of authority. Education and linguistic difference. Westport, Conn.: Greenwood Press, 2000. (Contemporary Studies in Linguistics and Education, David Bloome \& Jay Lemke, eds. Vol. $1)$.

Johnston, B., Kasper, G. and Ross, S. Effect of rejoinders in production questionnaires. Applied Linguistics, 19 (2): 157-182, 1998.

Kasper, G. Data collection in pragmatics research. In: Spencer-Oatey, H. (Ed.), Culturally speaking. Managing rapport through talk across cultures [Open Linguistics Series]. London \& New York: Continuum, 2000, pp. 316-341.

Mey, J. L. Pragmatics. An introduction. 2nd ed. Oxford \& Malden, Mass.: Blackwell, 2001. (1993)

Mey, J. L. Between culture and pragmatics. Scylla and Charybdis? The 
precarious condition of intercultural pragmatics. Intercultural Pragmatics, 1 (1): 27-48, 2004.

Mumby, D. K. \& Stohl, C. Power and discourse in organization studies. Absence and the dialectic of control. Discourse and Society, 2 (3): 313-332, 1991.

Sasaki, M. Investigating EFL students' production of speech acts. A comparison of production questionnaires and role plays. Journal of Pragmatics, 30 (4): 457484, 1998.

Searle, J. R. Indirect speech acts. In: Cole, P. \& Morgan, J. (Eds.) Syntax and semantics, Vol. 3: Speech acts, New York: Academic Press, 1975, pp. 59-82.

Yuan, Y. An inquiry into empirical pragmatics data-gathering methods. Written DCTs, oral DCTs, field notes, and natural conversations. Journal of Pragmatics, 33 (2): 271-292, 2001.

Professor Emérito da Universidade do Sul da Dinamarca e organizador do periódico Journal of Pragmatics. Pesquisador Visitante do CNPq na Universidade de Brasília em 2000, 2002 e 2004.

inmey@mail.utexas.edu 